\title{
2. Statistical needs in Indigenous affairs: the role of the 2002 NATSISS
}

\section{Jon Altman and John Taylor}

Over the last two years, Indigenous affairs policy at the national level has shifted direction dramatically: the central tenets of policy have shifted from terms such as self-determination, self-management and national Indigenous representation and advocacy to mainstreaming, mutual obligation, shared responsibility and a whole-of-government approach.

This broad change in direction has been predicated in large measure on a widespread perception that the socioeconomic situation of Indigenous people in Australia has, at worst, been a failure over the past 30 years or, at best, has not improved fast enough.

The new approach has been based on a growing emphasis on what has been termed 'practical reconciliation', or the pursuit of statistical equality between the standard of living of Indigenous and other Australians in the areas of health, housing, education and employment. In the foreword to the latest and influential Overcoming Indigenous Disadvantage: Key Indicators Report 2005, Productivity Commission Chairman Gary Banks refers to these issues as follows. Firstly, he notes the new determination by Australian governments to address the root causes of Indigenous disadvantage. Secondly, referring to the Prime Minister's speech at the National Reconciliation Conference, he identifies the shared goal [sic] that Indigenous people can ultimately enjoy the same standard of living as other Australians, for them to be as healthy, as long-living and as able to participate in the social and economic life of the country (SCRGSP 2005: iii).

We are almost certain that no-one would quibble with the need to address the causes of Indigenous disadvantage or the need for improvements in standards of living. A more lively debate might ensue about whether in the last 30 years any government has ever pursued objectives different to these; or whether the new approach is likely to be more successful than previous approaches. Arguably, it is difficult enough having conversations about what has worked and what has not in the past, let alone predicting what might be the best approach for the future.

Under such circumstances of policy contestation, one might anticipate that statistics collected by the official agency, the ABS, would play a crucial role in clarifying both the causes of Indigenous disadvantage and trends in Indigenous wellbeing, in absolute and relative terms. That is certainly one expectation that animated the conference 'Indigenous Socioeconomic Outcomes: Assessing Recent 
Evidence'. Our focus is on the 2002 NATSISS, the second social survey conducted by the ABS between August 2002 and April 2003. It is based on information collected from 9400 Indigenous Australians aged 15 years and over across all States and Territories of Australia (ABS 2004c: v).

The aims of this chapter are three-fold:

1. To provide some historical background about the emergence of this survey instrument by linking this conference to earlier workshops convened by CAEPR in 1992 and 1996 about the initial 1994 NATSIS.

2. To broadly examine the role and value of the 2002 NATSISS as one element of a broad ABS strategy to enhance the availability of statistics on Indigenous Australians.

3. To explore the longer-term role that the NATSISS instrument, now to be conducted every six years, might play in tracking Indigenous policy performance, informing Indigenous policy development, and in meeting the statistical needs of all stakeholder groups, including Indigenous Australians.

These three aims should be differentiated from the overall aim of the conference, which is to examine the 2002 NATSISS in great detail from a variety of methodological (e.g. coverage), thematic, and conceptual perspectives as the latest evidence about Indigenous socioeconomic outcomes. Then we anticipate some discussions of issues for consideration in developing the 2008 NATSISS. For these purposes, a wide array has been assembled of social scientists and Indigenous policy practitioners who are specialists in disciplinary areas.

\section{A brief history of the 1994 NATSIS and the 2002 NATSISS}

Conference participants were provided with two earlier monographs published by CAEPR, A National Survey of Indigenous Australians: Options and Implications (Altman 1992) and The 1994 NATSIS: Findings and Future Prospects (Altman \& Taylor 1996a). We summarise some salient issues from these monographs to provide a historical backdrop to this conference.

The first of these monographs reports the findings from a workshop, titled 'A National Survey of Aboriginal and Islander Populations', that was convened in April 1992. This was held, coincidentally, just a week after the Keating government committed $\$ 4.4$ million to the ABS to conduct a special national survey as outlined in recommendation 49 in the Final Report of the Royal Commission into Aboriginal Deaths in Custody (Commonwealth of Australia 1991). The workshop provided an early opportunity for the ABS to engage with a diversity of academics and Indigenous stakeholder groups about the conduct and potential content of such a national survey. 
The impetus for this recommendation in 1991 came from two directions. On one hand, the Royal Commission itself experienced an acute shortage of information about Indigenous Australians in its deliberations. In particular, its conclusions about the underlying factors that precipitated higher Indigenous incarceration were mainly drawn from the 1986 Census (Gray \& Tesfaghiorghis 1991). There was a strong view articulated by the Royal Commission that additional, and more timely, information about distinct and diverse social, demographic, health and economic characteristics of the Indigenous population was needed.

On the other hand, there was an equally strong view at the time that information was urgently needed at the just-established ATSIC Regional Council level to facilitate the development of regional plans and to gauge community infrastructure needs. It is interesting to note other policy drivers for a national survey and more statistical information on the situation of Indigenous Australians in 1992, including:

- a need for regional statistics so that Indigenous-specific programs could be better targeted to Indigenous people in greatest need

- debates about whether Indigenous-specific or mainstream programs were more efficient and effective

- a recognition of the need for more concerted and coordinated inter-governmental effort in Indigenous affairs, including the need for legally-binding bilateral agreements between the Commonwealth and the States, and

- a need for more information to inform the reconciliation process and track change in 'Indigenous disadvantage' over time.

The 1992 workshop ended with some recommendations both for the forthcoming 1994 NATSIS and for the collection of Indigenous statistics more generally. In terms of items to be included in the survey, there was a consensus view that a national survey should focus on distinct Indigenous issues not covered in other collections. Even by 1992, the ATSIC Housing and Infrastructure Needs Survey (Australian Construction Services 1993) was addressing many of the topics specified for inclusion by the Royal Commission. And there was a strong view expressed that a one-off survey would be of limited value without commitment to future surveys conducted on a similar and regular basis.

More importantly, it was highlighted that a national survey could not be an omnibus for all statistical needs about Indigenous Australians: there was a need for enhanced use of Indigenous identifiers in regular ABS household surveys, for greater availability of Indigenous identified information in administrative databases, and more information at the State and Territory level. Finally, there was a strong view that, while committing $\$ 4.4$ million for data collection was welcome, there was also a need for resources to ensure data analysis, publication 
and dissemination, especially at the regional level, to Indigenous stakeholders. $^{\text {l }}$

The second monograph reports the findings from the workshop 'Statistical needs for effective Indigenous policy: findings from the 1994 NATSIS'. This workshop was convened in late August 1996, just on nine years ago, not long after the new Howard government's 1996-97 Budget where it signaled its new direction in Indigenous affairs.

The workshop was convened to assess 1994 NATSIS outputs from academic, bureaucratic, Indigenous and ABS staff perspectives with a special focus on issues to be considered in the development of a future national survey. While the 1996 workshop examined NATSIS from a number of disciplinary perspectives that closely correlated with survey questions, it was not an evaluation of the survey, which had already been conducted by the ABS (1996b) itself (with input from CAEPR \& other stakeholders).

In considering the need for a repeat survey, the 1996 workshop, like this conference, sought open, constructive and rigorous scrutiny of the 1994 NATSIS. This is something that is not always easy to achieve, as new and innovative surveys evolve over time into statistical institutions with an identity and a sponsoring agency. Then, as now, the ABS, was an active and lively participant in proceedings.

As for the utility of the 1994 NATSIS, participants were acutely conscious of a fundamental dilemma: the more critical they were of particular questions, the greater the likelihood that questions would be modified or omitted, thus undermining the longer-term comparative utility of a future survey. The second workshop also examined what alternate sources of data were emerging that could be excluded from a repeat of the 1994 NATSIS, again highlighting that a national survey should not provide the means to 'statistically cost shift' from other household surveys where an Indigenous identifier might be justified (examples provided were the Labour Force Survey and the National Health Survey).

It is again interesting to note the political context of the 1996 workshop, when there was a perception that the new government might move to bifurcate its policy approach: targeting Indigenous-specific programs at remote regions and enhancing access to mainstream Commonwealth and State programs in non-remote contexts.

If this was a policy option then, it was only implemented by cutbacks to ATSIC Indigenous-specific programs as a contribution to the then overall 'deficit reduction plan'. It was highlighted in 1996 that the absence of statistics about

1 Expenditure on the 2002 NATSISS was approx \$4.5 million over four years: 2000-01 to 2003-04 (that is, from development through enumeration, processing and output). Most expenditure (that is, about $\$ 2$ million in field costs) was in enumeration year 2002-03. 
performance at the program level made agencies like ATSIC vulnerable to cutbacks and, conversely, that comparative statistics would be needed to hold governments accountable for their performance.

In this context, it was highlighted that the political economy of statistics - how statistics influence the distribution of public money-was important. ${ }^{2}$ This, in turn, influenced what information was to be collected, how Indigenous participation in the national survey was to be encouraged, and how the empowering information from a survey was to be analysed, accessed (taking into account income disparities and the ABS's user pays approach) and disseminated.

The 1996 workshop raised some important issues. Two that stand out in current policy debates are the need for information at appropriate regional levels, and the links between political and statistical cycles.

In relation to the former, it was noted that ATSIC regional council boundaries were liable to change and, in any case, might have limited utility given that the discretion available to the ATSIC Board of Commissioners to make regional allocations had declined significantly. While ATSIC has disappeared, it is still important to consider the appropriate regional jurisdictions for data collection.

On the latter, it was noted in 1996 that there would be an urgent need to monitor outcome changes in Indigenous affairs as policy takes new directions. While this observation may not have been heeded at the time, it certainly resonates with the contemporary situation. The 1996 workshop made three concluding recommendations:

- that there should be a repeat of the 1994 NATSIS, preferably in 1999 after a five-year interval, but that this should be leaner, meaner and sharper

- that careful consideration be given to maintaining some questions in the national survey that are comparable over time, while also allowing for new questions that allow comparability with other data sets, and

- that consideration be given to enhancing existing ABS household surveys to allow the identification of Indigenous participants in a statistically valid way that reflects their different geographic distribution. This is done, for example, with the Labour Force Survey once a year, but little is heard about the statistical outcomes.

Each of these issues could well be revisited in the context of this conference.

\footnotetext{
2 Having made this observation, one might question whether better statistically-based arguments would have altered the Australian Government's 'surplus distribution plan' in the run-up to the 2004 election.
} 


\section{The 2002 NATSISS in the overall statistical framework}

In the not-so-distant past, official processes served to exclude, devalue, and deter full Indigenous statistical representation. By contrast, the contemporary politics of data collection have sought to encourage inclusion via self-identification. This is manifest most recently in the greater involvement of Indigenous personnel in the collection of census and survey data, as well as in ministerial-level agreements for the adoption of a standard self-reported Indigenous status question in administrative collections.

In addition, the ABS has embarked on an ambitious Indigenous household survey and census program (see Table 2.1) that can trace its origin to the need for a government response to the findings of the 1991 Royal Commission into Aboriginal Deaths in Custody (Sims 1992).

As with other Indigenous-specific population surveys, such as the Western Australian Aboriginal Child Health Survey (Zubrick et al. 2004), this response is recognition of the need for non-standard approaches to developing census and survey content and methodology with an emphasis on Indigenous participation and, in some cases, control (Zubrick et al. 2004).

Complementing these enhanced census and survey initiatives, we now also have regular reporting of Indigenous outcomes from administrative data. In 2002, the Prime Minister wrote to Gary Banks as Chairman of the SCRGSP to produce a regular report to the COAG against key indicators of Indigenous disadvantage. This is now available on a biannual basis as the Productivity Commission Report Overcoming Indigenous Disadvantage. In addition, the annual Report on Government Services issued by the SCRGSP now includes a separate compendium of Indigenous statistics drawn from the administrative databases of Australian, State and Territory governments. 
Table 2.1. ABS Indigenous household surveys program: 1999-2011

\begin{tabular}{|c|c|c|c|}
\hline Year & Collection & Indigenous sample & $\begin{array}{l}\text { Level of geography } \\
\text { supported }\end{array}$ \\
\hline 1999 & Housing Survey (a) & 850-900 households & National \\
\hline 1999 & CHINS & $\begin{array}{l}\text { All discrete Indigenous } \\
\text { communities (approx. } \\
1300 \text { ) }\end{array}$ & Community level \\
\hline 2001 & $\begin{array}{l}\text { NHS (\& Indigenous } \\
\text { supplement) }\end{array}$ & $\begin{array}{l}\text { Indigenous sample of } \\
3400 \text { persons }\end{array}$ & National \\
\hline 2001 & CHINS & $\begin{array}{l}\text { All discrete Indigenous } \\
\text { communities (approx } \\
1300 \text { ) }\end{array}$ & Community level \\
\hline 2001 & $\begin{array}{l}\text { Population Census } \\
\text { Indigenous Enumeration } \\
\text { Strategy }\end{array}$ & All persons & Small geographic regions \\
\hline 2002 & NATSISS & 9400 persons & States/Territories \\
\hline 2004-05 & Indigenous Health Survey & 11000 persons & States/Territories \\
\hline 2006 & CHINS & $\begin{array}{l}\text { All discrete Indigenous } \\
\text { communities (approx. } \\
1300 \text { ) }\end{array}$ & Community level \\
\hline 2006 & Population census & All persons & Small geographic regions \\
\hline 2008 & NATSISS & 11000 persons & States/Territories \\
\hline $2010-11$ & Indigenous Health Survey & 11000 persons & States/Territories \\
\hline 2011 & $\begin{array}{l}\text { Population Census } \\
\text { Indigenous Enumeration } \\
\text { Strategy }\end{array}$ & All persons & Small geographic regions \\
\hline
\end{tabular}

Source: Adapted from www.abs.gov.au http:/true/truewww.abs.gov.au/true, Themes-Indigenous: Directions in Aboriginal and Torres Strait Islander Statistics, March 2000

While these developments clearly demonstrate rapidly enhanced collection and publication of statistical information, much basic information remains unavailable - not so much because data do not exist, but rather for want of appropriate planning frameworks. Viewed historically, there appears to be a growing gap between the scales at which Indigenous polities organise and plan, on the one hand, and the scales for which statistics are available, on the other. Thus, while we have never been so data-rich, leaving aside questions about the cultural relevance of the data, the information that is generated at great expense tends increasingly to be only useful for national, State and Territory level analysis, and/or broad remote/non-remote distinctions. There are a number of methodological, practical, and ultimately political dimensions to this observation.

First, from a methodological perspective, sample instruments such as the NATSISS and its companion General Social Survey (GSS) are best deployed to inform high-level policy discussion about the broad nature of inter-relationships between social circumstances and outcomes. Does crime impede employment prospects? Is health related to income? Do educated women have fewer children? For reasons of sample size and non-response error, they are less well suited to establishing absolute levels of need and comparisons over time.

Related to this is the fact that major constraints arise in relation to the geographic disaggregation of data to regional or community levels. Although the sample size of the adult population in the 2002 NATSISS was equivalent to that of the 
1994 NATSIS, data from the latter were released at the scale of 36 ATSIC regions, whereas the basic geography for 2002 comprises the remote and non-remote areas of the States and the Northern Territory (NT). The basic rationale for this shift is to be found in the trade-off between spatial detail and robustness of results.

Secondly, from a practical perspective, in terms of gathering administrative data, a combination of under-reporting, confidentiality provisions, and the grinding and increasingly guarded nature of bureaucratic processes render even the acquisition of data at State and Territory levels a major achievement (see Taylor \& Stanley 2005).

Finally, from a political perspective, the current paradigm for the collection and dissemination of Indigenous statistics is suited to the measurement and reporting of gaps. For the most part, this assists processes of government by bureaucrats in Canberra and the State capitals. This paradigm strongly reflects a deficit model of Indigenous socioeconomic need as measured by standard social indicators, and not a community development model. This approach suffers from all the pitfalls of averaging diverse circumstances leading to questions about the utility of data for Indigenous regional and community organisations and their members.

Worst of all, it lacks local Indigenous context. Demographers, for one, were warned some years ago of an imbalance between their statistical precision and detail, on the one hand, and their casualness of treatment of non-demographic contextual variables on the other (McNicoll 1988: 20 cited in Riedmann 1993: 107). Yet perennial problems about the ability of such an approach to capture cultural difference and the diversity of Indigenous circumstances looms yet again (Morphy 2002; Peterson 1996). As social scientists and policy practitioners, we need perhaps to revisit the original goal of the NATSISS instrument to capture information that is distinctly Indigenous and that can be made available at the regional level.

\section{NATSISS and Indigenous policy and practice}

Notwithstanding the above comments, there is no doubt that the 2002 NATSISS is already playing a role in broadly assessing Indigenous policy and practice.

The key task as defined by the SCRGSP is to identify indicators that are of relevance to all governments and Indigenous stakeholders and that can demonstrate the impact of program and policy interventions. In its overview, the SCRGSP (2005: xix) notes that its first report (2003) relied heavily on 2001 Census data, while the 2005 report has relied largely on 2002 NATSISS results. 
The SCRGSP is quite cautious in its use of 2002 NATSISS information, suggesting that:

- it is not comparable with earlier 2001 Census outcomes

- it comes from a period before the adoption of the reporting framework by governments, and

- it would not be reflecting outcomes from more recent interventions.

Nevertheless, the SCRGSP uses 1994 NATSIS and 2002 NATSISS information to make some broad observations about what has improved and what has not, although also basing much of its analysis on administrative data.

While this reporting of available information is instructive at a discursive level, it is very unclear how it demonstrates the impacts of program and policy interventions. Indeed, rigorous evaluations of specific policies targeting Indigenous Australians do not appear in the SCRGSP report and are largely missing in Indigenous policy discussions. It is generally recognised that interventions cannot be evaluated by comparing broad undifferentiated social indicator outcomes over time: programs and policies have to be evaluated at the micro target group community or regional level and there is little independent analysis of this kind in Australia today.

At one level, this statistical development is ironic given the government's recent focus on targeted regional COAG trial sites, SRAs and planned Regional Partnership Agreements, none of which have clearly defined evaluation mechanisms and associated data requirements. A notable exception here is the research undertaken at the Thamurrurr COAG trial site by Taylor (2004b) and Taylor and Stanley (2005) to gather baseline information that might inform evaluation. However, the intensity of research effort required to glean information at this level of disaggregation is instructive of the overall problem to which we are alluding - this research is expensive and not readily replicable.

At another level, this is symptomatic of the demise of a legally sanctioned (Indigenous) authorising environment for statistical collection and dissemination at regional levels, a role fulfilled until recently by ATSIC. The availability of ABS published outputs for ATSIC regions, co-signed by the Chair of the ATSIC Board and the Australian Statistician, was path-breaking (ABS 1995, 1996a). Unfortunately, this exercise in geographic disaggregation has not been repeated for the 2002 NATSISS.

In light of the ABS's own formal evaluation of the 1994 NATSIS, this last observation is significant. Among the key issues highlighted were the appropriateness of output mediums and the accessibility of results to Australia's Indigenous people and their organisations (Sarossy 1996). Findings on these matters raised the importance of regional level reporting and recommended that the dissemination strategy for any future survey should ensure that the results 
are readily available to the Aboriginal and Torres Strait Islander populations. To ensure this, it recommended that the ABS consider delivering basic statistical training in the interpretation of results to Aboriginal and Torres Strait Islander communities (Sarossy 1996: 192). This is now implicit in the ABS Indigenous Community Engagement Strategy implemented in 2004 (see Webster, Rogers \& Black, this volume).

To the extent that such recommendations are deemed to be still relevant, and with the demise of the ATSIC regional structure, the question has to be raised about what geographic scale of reporting is now appropriate. And with whom will the ABS engage in order to enhance the use of NATSISS information by Indigenous communities and organisations? Accessibility of survey data has been enhanced for academic and other researchers via the Australian Vice-Chancellors Committee (AVCC) agreement on data access and by the introduction of the Remote Access Data Laboratory (RADL). However, this enhancement is unlikely to benefit most Indigenous stakeholders, given the technical capabilities required and the fact that access to the CURF costs $\$ 8000$ for non-AVCC authorised users.

\section{Conclusion}

Without pre-empting the directions that discussions at this conference might take, we conclude with just a few complex issues of statistics and Indigenous public policy for consideration over the next two days.

Historically, the NATSISS instrument was established at a time when there was a recognised dearth of official statistics to document the socioeconomic situation of Indigenous Australians, though this is not to deny the importance of the five-yearly census - especially for comparison with the general population. In recent years, the ABS has greatly enhanced its Indigenous household survey and census program to the extent that in the 13 years 1999 to 2011, only three - 2000, 2007 and 2009-are survey free.

Despite this, there appears to be a growing and worrying mismatch between the broad direction that Indigenous affairs policy is taking on the one hand (focusing effort on partnerships with specific communities and regions), and the availability of non-census derived information. In particular, 2002 NATSISS data are not amenable to disaggregation to the regional level, unlike 1994 NATSIS data. This suggests that recent data might be of less value to Indigenous community and regional end-users and that comparative analysis between 1994 and 2002 will be impossible at the regional level.

This raises important issues of statistical accountability and the politics of statistics. From 1990-2005, there have been checks and balances on the increased ABS activity in this area, provided by its alliance with ATSIC. It is noteworthy that under s.7 of the Aboriginal and Torres Strait Islander Commission Act 1989, 
the ABS and ATSIC had a statutory relationship and that ATSIC was legally required to develop policy proposals to meet Indigenous needs and priorities from the national to the regional level. ATSIC was also required to assist, advise and cooperate with Indigenous communities, organisations and individuals, again to the regional level. Irrespective of ATSIC's capacity to effectively address such complex statutory functions, as a national representative organisation it did provide a degree of institutional authorisation to the Indigenous data collection and analysis activities of the ABS.

Today, we have a new partnership approach in Indigenous affairs, but we lack the statistical framework to assess its effectiveness. This situation might suit governments, but it also has the potential to entrench power and economic inequalities, especially for those Indigenous communities that might want to sign off on agreements in good faith and with the expectation of information to assess their effectiveness. We have already alluded to the emerging problems inherent in the absence of NATSISS data at the regional level. It is also clear that there is an emerging hierarchy of privileged access to 2002 NATSISS information, with the ABS being uniquely positioned in accessing Main Unit Record File (MURF) data at levels of disaggregation that are just not available publicly. ${ }^{3}$ Others, like the Productivity Commission, can purchase data, and academics can use the CURF without charge. Indigenous organisations and individuals appear least well placed to access such information. Such issues raise a number of important questions, with which we end:

- Is a survey instrument, like the NATSISS, sufficiently at arms-length from governments of the day?

- Bearing in mind the urgent need to track Indigenous wellbeing over time, what precise role will the 2008 NATSISS play in this process?

- Will 2008 NATSISS outputs, available in 2010, be helpful in adaptively managing the new approach in Indigenous affairs?

- Given that the 2002 NATSISS sample size was too small for regional disaggregation of findings, should the ABS look to augment the sample size in future?

- In the absence of a national Indigenous representative organisation, what institution will be empowered to ensure that official statistical information is collected that will help Indigenous communities and regions plan their futures?

3 See, for example, the analysis in Australian Social Trends 2005 at remote, very remote and discrete Indigenous communities (ABS 2005a: 52-57) that would be impossible for public users of 2002 NATSISS data to undertake. 